Canadian Journal of Applied Linguistics

\title{
Student Writers' Affective Engagement with Grammar-Centred Written Corrective Feedback: The Impact of (Mis)Aligned Practices and Perceptions
}

\section{Hooman Saeli and An Cheng}

Volume 22, Number 2, 2019

URI: https://id.erudit.org/iderudit/1065058ar

DOI: https://doi.org/10.7202/1065058ar

See table of contents

\section{Publisher(s)}

University of New Brunswick

ISSN

1920-1818 (digital)

Explore this journal

Cite this article

Saeli, H. \& Cheng, A. (2019). Student Writers' Affective Engagement with Grammar-Centred Written Corrective Feedback: The Impact of (Mis)Aligned Practices and Perceptions. Canadian Journal of Applied Linguistics / Revue canadienne de linguistique appliquée, 22(2), 109-132.

https://doi.org/10.7202/1065058ar

\section{Article abstract}

This project firstly explored Iranian English as a foreign language (EFL) students' perceptions about written corrective feedback (WCF)-related practices and preferences. Secondly, the student participants' first language (L1; e.g., Farsi) learner identities were operationalized, especially focusing on the skill of writing, WCF, and grammar-centred WCF. Thirdly, the students' affective engagement with WCF was scrutinized, particularly in light of L1 student identities. The participants in the study were 15 students in an Iranian EFL context. Analysis of interview data revealed that the skill of writing was held in low regard by the students. Also, several discrepancies emerged vis-à-vis WCF methods (e.g., direct vs. coded), error correctors (e.g., teacher feedback vs. peer feedback), the amount of correction (e.g., selective vs. comprehensive correction), and the relative importance of different components of writing (e.g., grammar vs. content vs. organization). In particular, the findings showed that the students' L1 identities involved low regard for writing, but high regard for speaking skills, and that they attached high value to grammatical accuracy and teacher explicit feedback. Finally, the findings indicated that: (a) the students' second language (L2) identities (e.g., WCF-related preferences) were profoundly affected by their L1 student identities, and (b) the discrepancies between the students' L2 writing preferences (e.g., preferred amount of WCF) and the teachers' reported practices could potentially hinder students' affective engagement with WCF.
Copyright (c) Hooman Saeli, An Cheng, 2019

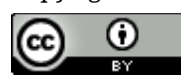

This document is protected by copyright law. Use of the services of Érudit (including reproduction) is subject to its terms and conditions, which can be viewed online.

https://apropos.erudit.org/en/users/policy-on-use/ 


\title{
Student Writers' Affective Engagement with Grammar-Centred Written Corrective Feedback: The Impact of (Mis)Aligned Practices and Perceptions
}

\author{
Hooman Saeli \\ The University of Tennessee, Knoxville \\ An Cheng \\ Oklahoma State University, Stillwater
}

\begin{abstract}
This project firstly explored Iranian English as a foreign language (EFL) students' perceptions about written corrective feedback (WCF)-related practices and preferences. Secondly, the student participants' first language (L1; e.g., Farsi) learner identities were operationalized, especially focusing on the skill of writing, WCF, and grammar-centred WCF. Thirdly, the students' affective engagement with WCF was scrutinized, particularly in light of L1 student identities. The participants in the study were 15 students in an Iranian EFL context. Analysis of interview data revealed that the skill of writing was held in low regard by the students. Also, several discrepancies emerged vis-à-vis WCF methods (e.g., direct vs. coded), error correctors (e.g., teacher feedback vs. peer feedback), the amount of correction (e.g., selective vs. comprehensive correction), and the relative importance of different components of writing (e.g., grammar vs. content vs. organization). In particular, the findings showed that the students' L1 identities involved low regard for writing, but high regard for speaking skills, and that they attached high value to grammatical accuracy and teacher explicit feedback. Finally, the findings indicated that: (a) the students' second language (L2) identities (e.g., WCF-related preferences) were profoundly affected by their L1 student identities, and (b) the discrepancies between the students' L2 writing preferences (e.g., preferred amount of WCF) and the teachers' reported practices could potentially hinder students' affective engagement with WCF.
\end{abstract}

\section{Résumé}

Premièrement, cette étude a examiné les préconceptions d'élèves iraniens apprenant l'anglais comme langue étrangère (ALE) par rapport à la rétroaction corrective écrite (RCE), aux pratiques qui y sont liées et aux préférences. Deuxièmement, les identités des apprenants dans leur langue première (L1 ; p. ex. le farsi) ont été opérationnalisées, se concentrant spécialement sur les habiletés écrites, la RCE et la RCE centrée sur la grammaire. Troisièmement, l'implication affective des apprenants envers la RCE a été examinée, notamment en matière des identités en L1 des participants. Quinze élèves iraniens d'un contexte d'ALE ont participé à l'étude. Les analyses de données des entrevues ont révélé que les élèves accordaient peu d'importance à l'écrit. De plus, plusieurs divergences ont émergé par rapport aux méthodes de RCE (p. ex. directe vs codée), les correcteurs d'erreurs (p. ex. rétroaction de l'enseignant vs la rétroaction des pairs), le montant de correction ( $\mathrm{p}$. ex. sélective vs intégrale) et l'importance relative des différentes composantes de l'écrit (p. ex. grammaire vs contenu vs organisation). Notamment, les résultats ont démontré que les 
identités de L1 des élèves attribuaient peu de valeur à l'écrit, mais qu'elles tenaient les compétences à l'oral en haute estime. Aussi, ces identités accordaient beaucoup de valeur à la précision grammaticale et à la rétroaction explicite de l'enseignant. Finalement, les résultats ont révélé (a) que les identités en langue seconde des élèves (L2; préférences liées à la RCE) étaient étroitement liées à leurs identités en L1 et (b) que les divergences entre les préférences d'écriture en L2 des élèves (p. ex. montant de RCE) et les pratiques rapportées des enseignants pourraient potentiellement entraver l'implication affective des élèves avec la RCE.

\section{Student Writers' Affective Engagement with Grammar-Centred Written Corrective Feedback: The Impact of (Mis)Aligned Practices and Perceptions}

\section{Background}

\section{Introduction}

Feedback is the corrective commentary on different aspects of student writing, such as content, rhetorical organization, mechanics, and grammar (Sheen, 2007). For over three decades, written corrective feedback (WCF) has been studied as a means of improving second language (L2) learners' grammatical accuracy (henceforth in this manuscript WCF only refers to corrective commentary on grammatical errors in writing). After Truscott (1996) called for abandoning grammar correction in student writing, in her rebuttal Ferris (1999) argued for the benefits of WCF in reducing students' grammatical errors. Motivated by the conceptual and empirical evidence for the incorporation of WCF, numerous studies have examined the differential effects of grammar correction methods on learners' accuracy gains in writing, hoping to provide practical recommendations for teachers (e.g., Bitchener, Young, \& Cameron, 2005; Chandler, 2003; Fazio, 2001; Sheen, Wright, \& Moldawa, 2009; Yang, Badger, \& Yu, 2006). However, this emphasis on the experimental aspects of WCF methods, as Lee (2008) concurred, has largely neglected L2 learners' feedback-related perceptions and preferences, thereby viewing these learners as passive users of WCF. In response to this shortcoming, several studies have investigated learners' perceptions and preferences regarding grammar correction (e.g., Ferris, 1995; Hedgcock \& Lefkowitz, 1994; Lee, 2005; Radecki \& Swales, 1988). These studies have depicted L2 learners as active recipients of WCF who can take an active role in providing and using this feedback in increasing their grammatical accuracy.

\section{L2 Learners' Perceptions about WCF}

The existing research suggests that L2 learners' perceptions about WCF (e.g., feedback sources and correction methods) can affect the attainment of accuracy gains (Lee, 2008). Several studies have examined these perceptions. For instance, Leki (1991) examined 100 English as a second language (ESL) students' perceptions about WCF. She concluded that her students (a) strongly preferred accurate grammar in writing, (b) usually reviewed the received $\mathrm{WCF}$, and (c) liked to receive comprehensive, teacher-generated WCF. In another study, Ferris (1995) surveyed 155 ESL students' WCF-related perceptions. Her results revealed that these learners viewed teacher-generated WCF, but not peer feedback, as an essential feedback source. These participants "felt they received the most comments on grammar, followed (in this order) by organization, content, mechanics 
(defined for the students as spelling, punctuation and capitalization), and vocabulary" (Ferris, 1995, p. 40). Additionally, Lee (2008) studied English as a foreign language (EFL) student writers' perceptions about WCF in Hong Kong. Her results indicated that these students preferred to receive teacher-generated, direct WCF, even though such types of feedback would make students over-rely on teachers for improvement. Overall, the above studies suggest that L2 students generally prefer teacher-generated, comprehensive grammar-centred WCF in writing, although the existing literature recommends the incorporation of more learner-centred WCF approaches (e.g., Ferris, 2014; Lee, 2008).

A smaller group of feedback studies have compared students' perceptions with their teachers' practices. For instance, Montgomery and Baker (2007) aimed to identify any WCF-related discrepancies between teachers' practices and students' perceptions by analyzing questionnaire data and samples of student writing. They noticed that teacher practices were consistent with student perceptions, although the teachers provided less WCF than what the students thought they had received. Schulz (2001) compared student and teacher preferences regarding WCF and grammatical accuracy in Colombian and U.S. contexts. She concluded that, although the teachers and students agreed on the importance of grammatical accuracy, the students valued grammatical accuracy more highly than the teachers did. A number of perceptions (e.g., the importance of grammatical accuracy) were caused by the sociocultural differences between Colombia and the United States. The above studies show that teacher practices and student perceptions might be frequently misaligned, that these misalignments can negatively affect the attainment of grammatical accuracy (see also Han \& Hyland, 2015), and that sociocultural factors can affect student and teacher perceptions about WCF.

\section{Learners' WCF-Related Perceptions, Learners' Engagement With WCF, and Efficacy of WCF}

The recent focus on student writers and their perceptions has led researchers to examine learners' feedback-related perceptions and effects of these perceptions on WCF efficacy. Rummel and Bitchener (2015) concluded that students' feedback-related perceptions play an important role in improving their grammatical accuracy. They suggested that favourable perceptions can improve the uptake of grammatical structures (i.e., simple-past tense), thus the efficiency of WCF. Rummel and Bitchener reported that positive perceptions about WCF might lead to the allocation of cognitive resources (e.g., focal attention) in the subsequent incorporation of corrected forms in student writing. Similarly, Han (2017) linked L2 students' perceptions to the effectiveness of WCF, stating that positive perceptions can lead to the attainment of grammatical accuracy. Han touched on the impact of learners' perceptions on the efficacy of WCF. These two studies suggest that learners' positive perceptions about feedback affect their positive engagement with WCF. This has motivated a few studies to scrutinize learners' perceptions, preferences, and expectations regarding $\mathrm{WCF}$, their reactions to received $\mathrm{WCF}$, and their allocation of cognitive resources to the use of WCF. Ellis (2010) called these elements learners' engagement with feedback. Ellis posited that learning takes place if learners engage positively with feedback. He operationalized "learner engagement" as comprising:

a cognitive perspective (where the focus is on how learners attend to the $\mathrm{CF}$ [corrective feedback] they receive), a behavioral perspective (where the focus is on 
whether and in what way learners uptake oral corrections or revise their written texts), and an affective perspective (where the focus is on how learners respond attitudinally to the CF). (p. 342)

Ellis (2010) and Han and Hyland (2015) concluded that learners' positive engagement with feedback is essential to increasing their grammatical accuracy. Of central importance to our study is learners' affective engagement with WCF. Han and Hyland (2015) defined affective engagement as "(a) Immediate emotional reactions upon the receipt of WCF and changes in these emotions over the revision process, [and] (b) Attitudinal responses toward WCF" (p. 33). In this study we focus on learners' attitudinal reactions toward feedback. Han and Hyland pointed out that learners' affective engagement with feedback can be negatively influenced by discrepancies in teacher practices and student perceptions. These authors posited that if learners receive some feedback that they do not view as effective or desirable, they may not incorporate it in their subsequent writing attempts and/or may not allocate sufficient cognitive resources to it.

A few empirical studies have examined the impact of learners' affective engagement with feedback on the efficacy of WCF. Analyzing samples of student writing and interview responses, Zhang and Yu (2018) concluded that students' positive affective engagement with feedback was important in increasing their grammatical accuracy. However, the results showed that the students' low proficiencies superseded their positive affective engagement with feedback, thereby limiting the actual effects of positive affective engagement on accuracy gains. Additionally, examining student perceptions about direct, indirect, and metalinguistic WCF, Rummel and Bitchener (2015) concluded that the noticeable increases in their students' grammatical accuracy (i.e., simple-past tense) would not have occurred "if beliefs had not had some effect on learners' uptake of the written CF they received" (p. 79). Overall, these studies underscore the effect of learners' positive perceptions about WCF on their affective engagement with feedback. Positive perceptions, as these studies show, usually lead to positive cognitive and behavioural engagement with WCF, which can in turn improve learners' gains in grammatical accuracy.

Because L2 student writers' affective engagement is usually their first reaction to the WCF they receive, we, similar to Han (2017), believe that this response has significant bearings on the ultimate effectiveness of WCF and students' gains in grammatical accuracy. However, despite its importance, affective engagement with feedback, as Han and Hyland (2015) agreed, has received very little empirical attention in the existing feedback literature. Therefore, we set out to qualitatively explore Iranian EFL students' perceptions about WCF, as well as their perceptions about their teachers' WCF practices. Perceptions, in our case, are similar to "attitudinal responses to WCF" (p. 32) in Han and Hyland's (2015) discussion of affective engagement. Specifically, we hoped to investigate whether our participating student writers' feedback-related perceptions influenced their affective engagement with different aspects of WCF, while focusing on any discrepancies between their perceptions and their teachers' reported practices.

\section{Iranian EFL Students' Perceptions About WCF}

The Iranian EFL context is unique, and such uniqueness deserves further investigation. Farhady, Hezaveh, and Hedayati (2010) reported that textbook-based English classes are offered in the Iranian school system. The outcomes of this education system, 
however, remain unsatisfactory because both teaching and assessment are centred around discrete grammar rules, vocabulary lists, and reading comprehension, leaving very little, if any, room for writing-related activities. The English education system in Iran, as Farhady, Hezaveh, and Hedayati suggesed, usually influences the perceptions of both teachers and students about various aspects of English teaching and learning (e.g., L2 writing). Specifically, Saeli and Cheng (2019) showed that Iranian EFL learners' first language (L1) writing experiences are significant determiners of their perceptions about L2 writing. Given this strong influence of the educational system on Iranian teachers and students about various aspects of English learning, the Iranian EFL context in general and Iranian teachers and students' perceptions about English language learning in particular deserve a closer look. In fact, understanding a unique English language teaching (ELT) context such as Iran would help us understand other ELT contexts better through comparisons and contrasts.

Iranian EFL students' perceptions about different aspects of language learning have received some attention (e.g., Haseli Songhori, 2012; Shishavan, 2010; Shishavan \& Sadeghi, 2009), a line of research we hope to continue in the present study. For example, despite the relative dearth of empirical research on WCF in the Iranian EFL context, a few studies have examined teachers' and students' perceptions about WCF. Jodaie, Farrokhi, and Zoghi (2011) surveyed student and teacher perceptions about WCF and grammatical accuracy in writing. The results showed that both groups strongly valued improvements in grammatical accuracy through teacher-generated, comprehensive, and direct WCF. Rahimi (2010) explored students' perceptions about grammatical accuracy and aspects of WCF (e.g., correction method, amount, and source). The results revealed that the students tended to value grammatical accuracy and teacher-generated WCF. These studies, however, provided mostly quantitative accounts of Iranian EFL students' WCF-related perceptions and preferences. We need to complement such quantitative accounts with more in-depth, qualitative accounts of Iranian learners' affective engagement with feedback through qualitative research methods such as interviews that are inherently useful for exploring learners' thoughts, perceptions, and rationales about WCF.

\section{The Present Study}

The present study was motivated by two shortcomings we noticed in the literature. First, learners' WCF-related perceptions have been shown to improve the efficacy of WCF in increasing students' grammatical accuracy in writing (e.g., Han \& Hyland, 2015). However, research on such perceptions is relatively scarce (e.g., Elwood \& Bode, 2014; Leki, 2001), especially in the Iranian EFL context. As discussed earlier, these contexts have unique characteristics, and understanding such uniqueness may help us, through comparison and contrast, to understand other ELT contexts. Second, researchers have only recently started to investigate learners' affective engagement with WCF, so only a few studies exist on learner engagement with feedback (e.g., Han, 2017; Zheng \& Yu, 2018). As a result, we need to examine learners' feedback-related perceptions and identify any discrepancies between these perceptions and teachers' WCF-related practices. Such an investigation, in turn, helps shed light on learners' affective engagement with different 
aspects of WCF (e.g., WCF selectivity, methods, and sources). Therefore, we set out to answer the following questions in our study:

1. How do the Iranian EFL students we studied perceive various aspects of WCF?

2. How do these students perceive their teachers' WCF practices?

3. Are there any discrepancies between student perceptions and teacher practices when it comes to WCF? If yes, what is the impact, if any, of such discrepancies on students' reported affective engagement with WCF?

\section{Methodology}

\section{Setting and Participants}

Our study was conducted in two English schools in Iran. The first school had approximately 20 teachers and 350 students per semester, and the second one had about 35 instructors and 750 students per semester. Both schools offered test-preparation (e.g., Test of English as a Foreign Language Internet-Based Test [TOEFL iBT] and International English Language Testing System [IELTS]) and general English courses (i.e., focused on all four skills), adopted a textbook-based curriculum, and aimed for consistency in instruction and assessment across different sections through teacher development procedures such as workshops and handbooks. For example, in terms of writing and feedback, all teachers were asked to assign and provide feedback (e.g., grammar and content) on three to five major writing assignments every semester, along with shorter writing tasks and in-class activities.

Our data were collected from 15 students. Table 1 provides the relevant background information on the participants. All names are pseudonyms and test-prep courses refer to TOEFL iBT and/or IELTS preparation.

The proficiency levels for students are based on institutional guidelines. At the time of the data collection, for instance, the proficient use of the present tense, but not the past tense, at a sentence level would place a learner in a lower-intermediate class. The ability to use the present, past, and future tenses would place a learner in a higher-intermediate class. The placement criteria comprised measures of accuracy, complexity, and fluency, each of which were allocated 10 points, making up a total of 30 . At the time of the data collection. these guidelines were the following:

- 0-5: beginner

- 6-10: lower-intermediate

- 11-15: intermediate

- 16-20: upper-intermediate

- 21-25: pre-advanced

- 26-30: advanced

Our participant selection criterion was experience in taking EFL classes where writing was taught and assessed. Since both English schools required the teaching and assessment of writing in both their four-skills and test-prep classes, we assumed that the participating students satisfied our recruitment criterion. 
Table 1

Participants' Background Information

\begin{tabular}{|c|c|c|c|c|c|c|}
\hline \multicolumn{3}{|c|}{ Personal Information } & \multicolumn{4}{|c|}{ English and Academic Background } \\
\hline Name & Gender & Age & $\begin{array}{c}\text { Proficiency } \\
\text { Level }\end{array}$ & $\begin{array}{c}\text { Years } \\
\text { Studying } \\
\text { English }\end{array}$ & $\begin{array}{l}\text { English } \\
\text { Courses }\end{array}$ & $\begin{array}{l}\text { Academic } \\
\text { Major }\end{array}$ \\
\hline Ari & Male & $20 \mathrm{~s}$ & $\begin{array}{l}\text { Lower } \\
\text { intermediate }\end{array}$ & 4.5 & Four-skills & $\begin{array}{l}\text { M.S. in } \\
\text { Engineering }\end{array}$ \\
\hline Ava & Male & $20 \mathrm{~s}$ & Advanced & 17 & $\begin{array}{l}\text { Four-skills } \\
\text { and test-prep }\end{array}$ & $\begin{array}{c}\text { M.S. in } \\
\text { Engineering }\end{array}$ \\
\hline Eddy & Female & $20 \mathrm{~s}$ & $\begin{array}{c}\text { Upper } \\
\text { intermediate }\end{array}$ & 12 & Four-skills & $\begin{array}{l}\text { B.S. in Hard } \\
\text { Sciences }\end{array}$ \\
\hline Faezeh & Female & $30 \mathrm{~s}$ & Intermediate & 10 & $\begin{array}{l}\text { Four-skills } \\
\text { and test-prep }\end{array}$ & $\begin{array}{l}\text { Ph.D. in Hard } \\
\text { Sciences }\end{array}$ \\
\hline Hoji & Male & $20 \mathrm{~s}$ & Advanced & 7 & $\begin{array}{l}\text { Four-skills } \\
\text { and test prep }\end{array}$ & $\begin{array}{l}\text { M.S. in } \\
\text { Engineering }\end{array}$ \\
\hline Ladan & Female & $30 \mathrm{~s}$ & Advanced & 12 & $\begin{array}{l}\text { Four-skills } \\
\text { and test prep }\end{array}$ & $\begin{array}{c}\text { M.A. in } \\
\text { Management }\end{array}$ \\
\hline Mahnaz & Female & $20 \mathrm{~s}$ & $\begin{array}{l}\text { Lower } \\
\text { intermediate }\end{array}$ & 8 & Four-skills & B.A. in Law \\
\hline Majid & Male & $30 \mathrm{~s}$ & Intermediate & 13 & Four-skills & $\begin{array}{c}\text { B.S. in } \\
\text { Engineering }\end{array}$ \\
\hline Maria & Female & $30 \mathrm{~s}$ & $\begin{array}{c}\text { Upper } \\
\text { intermediate }\end{array}$ & 6 & $\begin{array}{l}\text { Four-skills } \\
\text { and test prep }\end{array}$ & $\begin{array}{c}\text { B.A. in } \\
\text { Mathematics }\end{array}$ \\
\hline Mary & Female & $30 \mathrm{~s}$ & $\begin{array}{c}\text { Upper } \\
\text { intermediate }\end{array}$ & 9 & Four-skills & B.S. in Science \\
\hline Nely & Female & $30 \mathrm{~s}$ & $\begin{array}{c}\text { Upper } \\
\text { intermediate }\end{array}$ & 26 & Four-skills & $\begin{array}{l}\text { Ph.D. in } \\
\text { Humanities }\end{array}$ \\
\hline Omid & Male & $30 \mathrm{~s}$ & $\begin{array}{c}\text { Upper } \\
\text { intermediate }\end{array}$ & 2.5 & Four-skills & MBA \\
\hline Samaneh & Female & $20 \mathrm{~s}$ & Advanced & 11 & $\begin{array}{l}\text { Four-skills } \\
\text { and test prep }\end{array}$ & MBA \\
\hline Sara & Female & $20 \mathrm{~s}$ & $\begin{array}{l}\text { Upper } \\
\text { intermediate }\end{array}$ & 13 & $\begin{array}{l}\text { Four-skills } \\
\text { and test prep }\end{array}$ & $\begin{array}{l}\text { M.A. in } \\
\text { Economics }\end{array}$ \\
\hline Zohreh & Female & $20 \mathrm{~s}$ & Advanced & 10 & $\begin{array}{l}\text { Four-skills } \\
\text { and test prep }\end{array}$ & $\begin{array}{l}\text { M.A. in } \\
\text { Economics }\end{array}$ \\
\hline
\end{tabular}




\section{Data Collection Instrument, Procedure, and Analysis}

Our data collection instrument was a semi-structured interview (see the questions in the Appendix). We adopted and adapted several questions from Ferris (2014) and developed some additional questions after consulting with three instructors experienced in teaching and assessing writing in the Iranian EFL context. The interviews comprised four major sections covering students' perceptions about

- different aspects of WCF,

- their teachers' respective WCF practices,

- any discrepancies between their own perceptions and their teachers' practices they noticed, and

- their affective engagement with various aspects of WCF.

We asked the students to review their last three essays with feedback on them to arrive at a better understanding of their teachers' WCF practices, their own perceptions, and any areas of discrepancy between such perceptions and practices. Specifically, we aimed to examine the students' affective engagement with WCF by exploring their perceptions and expectations about the WCF they preferred to receive versus the WCF they actually received.

To recruit the participants, we asked several instructors to provide the consent forms to their students. We invited 75 students to take part in the interviews and 15 of them volunteered to do so. After the participants returned the signed consent forms, they picked their convenient times and locations for the interviews and were reassured that the interviews would be conducted in Farsi. We began the interviews with a short introduction and then collected the participants' relevant background information, shown in Table 1. After asking several questions about the students' WCF-related perceptions, their teachers' practices, and their affective engagement with $\mathrm{WCF}$, we concluded the interviews. The approximate lengths of the interviews were 35 to 70 minutes. All the responses were transcribed in Farsi and later translated into English by the first author. We adhered to some of the basic tenets of interview data analysis and grounded theory analysis (see Corbin \& Strauss, 2014), analyzing the data by going through several stages of coding and looking for recurring themes in the data. Guided by our interview questions, we developed a number of thematic categories from our data analysis. We present and discuss these categories in the following section.

\section{Findings and Discussion}

In this section, we present and discuss the findings. Here, we differentiate between the students' own perceptions (perception) and their teachers' practices as perceived by these students (perceived practice) to identify any areas of discrepancy. Whenever necessary or helpful, we have added our interview questions and/or interpretation of the interview responses using brackets. All the reported frequencies are out of 15 unless otherwise is mentioned. As noted earlier, in this study we use WCF to refer to only corrective commentary on grammatical errors. 


\section{Perceptions About the Relative (Lack Of) Importance of WCF in L2 Writing}

Our first finding was related to whether or not our student participants perceived WCF as important, when compared with how they viewed the importance of feedback on content and organization in writing. The data analysis showed that only a few students $(n=3)$ prioritized grammar feedback over feedback on content and organization. By contrast, a large majority $(n=12)$ reported that feedback on content development and/or organization was more important to them than WCF (perception). Interestingly, all the participants $(N=15)$ claimed that their teachers prioritized feedback on grammar over content and organization in their actual practices, and many students $(n=11)$ pointed out that they received less feedback on content and organization than what they believed to be sufficient (perceived practice). In Excerpt 1, Ari, a general-English lower-intermediate student, explained why he prioritized feedback on content development over grammarcentred WCF in writing. Although Ari stated that content development was important in the writing section of the TOEFL iBT, his teachers reportedly provided extensive WCF to increase his grammatical accuracy.

Excerpt 1: My personal preference is to be able to communicate my ideas well ... I want to be able to develop strong content in my writing. I'm sure I need that on TOEFL. . . I think it's bad to just focus on grammar when our content isn't good. [How do you rank-order your own feedback preferences?] I first want to work on my content. I think I haven't been taught how to do it. . . . Having some grammatical errors in writing is normal. I think you can still communicate, even with some grammatical errors. . . . [How do your teachers prioritize feedback?] They mostly give feedback on grammar. . . . They're more sensitive about grammar. I care less about it [WCF]. Maybe my knowledge [about language learning] is not high enough. ... [How do you evaluate the feedback you receive?] I think it's too much on grammar. Like I said, I want to improve my content, but rarely get any comments on it. ... [What do you do if your teacher provides too much grammar correction?] I sometimes ignore some grammar comments because I know the correct forms myself. I don't think good writing only needs to be [grammatically] accurate. (Ari, interview transcript, pp. 87-88)

In Excerpt 1, Ari evaluated his teachers' feedback practices rather negatively and even went so far as to state that he would sometimes ignore his teachers' WCF on some of his grammatical errors. This excerpt shows a discrepancy between Ari's own preferences and his teachers' practices as perceived and reported by him. We can see that his affective engagement with excessive WCF was likely to be negative because he said he would sometimes ignore his teachers' overemphasis on grammatical accuracy.

Similarly, Zohreh, an advanced student in test-prep and general-English classes, stated that developing rich content was more important to her than merely focusing on grammatical accuracy. In fact, it is quite interesting to note that because Zohreh reported she had always struggled to improve her grammatical accuracy, she had become resigned to the fact that having some grammatical errors in writing was "normal." Even with what she reported as her struggle with grammatical accuracy, she, quite ironically and quite interestingly to us, reported that she preferred comments on content. Excerpt 2 presents Zohreh's perceptions and her teachers' practices as she perceived and reported them. 
Excerpt 2: Content [development] has always been more important in my mind, rather than just having correct grammar. I think it's more important to see what you are actually talking about [in writing]. ... [How about grammatical accuracy?] Grammar has always been difficult to me. Always volatile .. . I've taken many English classes but usually forget about the grammar I've learned. I used to check grammar books and dictionaries before turning in essays to have accurate grammar. ... But it never worked. I always got my essays back with lots of grammar comments. So, now I think it's normal to have some grammar errors. Now, what's more important is having good ideas. ... [How about your teachers' feedback practices?] They've always taught grammar using textbooks. . . . Same thing for feedback. They always correct every grammar error I have. . . I think my teachers should guide me more about content development. It's not like I don't like good grammar, but content is sacrificed sometimes. .. . [How do you react to this emphasis on grammatical errors?] I don't ignore it [WCF], but I don't pay attention to every single correction either. (Zohreh, interview transcript, pp. 149-151)

As shown in Excerpt 2, while Zohreh reported that she liked to receive more feedback on content, she noticed that her teachers provided her with comprehensive WCF. Similar to Ari in Excerpt 1, we can see that Zohreh's affective engagement with her teachers' comprehensive WCF is likely to be negative. In fact, she stated that she did not pay attention to every detail in what she perceived to be her teachers' overcorrection of her grammatical errors.

In Excerpt 3, Nely, an upper-intermediate student in a general-English class, reported that proper organization and content development were very important to her, while grammatical accuracy was her last priority.

Excerpt 3: [For me] organization in the first place; then content. Grammar is last. Grammar is important; as long as you get across your thoughts, [using] some normal structures [accurately] would be enough. ... I think it's fine to have some grammar errors in writing. We can't be perfect [grammatically accurate]. . . . [Why is organization the most important to you?] Because I'm good at [developing] content. I've always been good in my Farsi writing, too. Grammar doesn't need to be perfect. But I need help with organization. I try to read samples, but in the end, I'll need my teacher's feedback [on organization]. . . . [How about your teachers' WCF practices?] For teachers, the fact that we could use the newly learned grammatical structures [accurately] in new writings is more important [than content and organization]. They want us to use grammar accurately. Then, the appearance of writing, like margins and word count. But content hasn't been very important ... [How do you react to your teachers' correction of grammatical errors?] I honestly don't need to be told too many times about my grammar errors. I usually look at the corrections, but don't get that deep [-ly engaged]. (Nely, interview transcript, pp. 132-133)

As revealed in Excerpt 3, Nely negatively assessed the comprehensive WCF she received. Although she believed that having some grammatical errors in writing was normal, her teachers reportedly overemphasized grammatical accuracy. This discrepancy 
showed that she did not "deeply" engage with the received WCF because she preferred more feedback on organization and content. Similar to Excerpts 1 and 2, Nely's affective engagement with her teachers' WCF was most probably negative.

By contrast, Mary, an upper-intermediate student in a general-English class, stated that WCF was her desired feedback type and that the most important aspect of student writing was grammatical accuracy. Excerpt 4 shows Mary's accuracy-oriented perceptions.

Excerpt 4: [What are your feedback priorities?] Grammar, content, and then organization [in that order]. I want all three of them, but grammar is more important. If your grammar is good, your speaking and writing will improve. . . I believe without accurate grammar, you cannot convey your thoughts. No matter how sophisticated they [ideas] are. [Why content is not your priority?] Because students often have good contents. But knowing how you should use grammar [accurately] is more difficult. ... Good content needs good grammar first. Without good grammar, no one will understand what you say [in writing]. . . . [How do you evaluate your teachers' feedback practices?] I think using newly learned grammatical structures accurately [is their priority]. . . . No matter what, they always wanted us to use grammar accurately. Content isn't that important to them. ... [How do you react to your teachers' correction of grammatical errors?] I think they know better, so I do my best to review their corrections at least once. (Mary, interview transcript, p. 128)

In Excerpt 4, Mary explained that content development in writing is dependent upon accurate grammar. She also claimed that increasing her grammatical accuracy was more difficult than developing rich content. Because Mary's own and her teachers' feedback priorities were well-aligned (i.e., focusing on WCF), her affective engagement with the received WCF was likely to be positive, especially compared with Ari, Zohreh, and Nely. Overall, our findings in this section reveal that our participants

- mostly claimed to prioritize feedback on content and organization,

- reportedly received extensive grammar feedback,

- brought up feedback-related discrepancies between their own perceptions and what they reported to be their teachers' practices, and

- mostly affectively engaged negatively with the received WCF due to the discrepancies noticed above.

We can think of two reasons behind the reported popularity of feedback on content and organization in our study. First, of our 12 participants who prioritized feedback on content and organization over WCF, the majority $(n=11)$ believed that having some grammatical errors in writing was normal if these errors did not affect the communication of ideas. Second, one student stated that she valued feedback on content and organization because of reportedly failed attempts at improving her grammatical accuracy (see Excerpt 2).

While our participants $(n=12)$ highly valued feedback on content and organization in writing, several studies have acknowledged Iranian EFL students' strong preference for increasing their grammatical accuracy, such as in Ganjabi (2011), whose student participants highly valued teacher-generated grammar feedback. In other L2 contexts, Kern 
(1995) and Horwitz (1999) showed that nearly half of their students attached the highest importance to grammar in language learning.

\section{Perceptions About Comprehensive and Selective WCF in L2 Writing}

This section reports on the students' perceptions about the comprehensiveness of the WCF they received. We discussed their perceptions on this issue based on what these students pointed out as two types of practices often adopted by their teachers when they offered WCF:

- comprehensive WCF: correction of all grammatical errors in student writing, irrespective of error type and error frequency;

- selective WCF: correction of certain types and a certain number of grammatical errors in student writing, depending on error type and error frequency.

Our data analysis indicated that the majority of the students $(n=10)$ reported that they preferred to receive comprehensive WCF on all their grammatical errors, irrespective of error type and frequency. These students pointed to their low grammatical proficiency in justifying their preferences for comprehensive WCF (perception). In addition, most of the participants $(n=12)$ believed that their teachers also provided comprehensive WCF on all their grammatical errors in writing (perceived practice). In Excerpt 5, Samaneh, an advanced student in test-prep and general-English classes, stated that even though she noticed that her teachers had previously used selective WCF in writing, this WCF approach was not desirable to her. Samaneh preferred comprehensive WCF because she did not view her grammatical competence as sufficiently high to identify and correct her own grammatical errors in writing.

Excerpt 5: What we did in one of class was that our teacher sometimes corrected some errors, but left some for us to correct. I learned better when my teacher corrected all the errors. When I was on my own to correct the errors, I think I wasn't that good at it. So, I always thought I repeated all my [grammatical] errors over and over again. . . . I believe I need the correction of all my errors if I want to learn something. ... [How about your teachers' practices?] They correct them [grammatical errors] all. ... I personally don't pay a lot of attention to correct all my errors. If they [teachers] correct all errors, that'd be better. If not, I wouldn't think I had other errors [which I could not identify]. . . . One of my teachers once told me it helps with long-term learning if I can correct some errors myself, but if I don't know what and where the errors are, how can I learn anything? I don't like to be in charge [of correcting grammatical errors]. (Samaneh, interview excerpt, $p$. 141)

In Excerpt 5, Samaneh reported that her teachers generally provided comprehensive WCF on her grammatical errors in writing. Even though she brought up some instances in which her teachers had used selective WCF, her evaluation of such an approach was negative because of her reported lack of grammatical competence. In general, it seemed that Samaneh's WCF-related perceptions and her teachers' practices regarding feedback 
selectivity were well-aligned. This alignment suggests that her affective engagement with comprehensive WCF was probably positive. By contrast, in Excerpt 6, Nely, an upperintermediate student in a general-English class, pointed out that selective WCF was desirable to her because, unlike Samaneh, she preferred to be actively involved in the process of increasing her grammatical accuracy in writing. She claimed that comprehensive WCF would turn her into a passive recipient and user of feedback.

Excerpt 6: I don't like all my [grammatical] errors to be corrected. I want to be able to correct some of them on my own. ... I think when my teachers correct all errors, you just sit there and receive the corrections. You might not learn anything because you're not that much involved in it [correction process]. I've always learned better when I'm an active part of the learning process. I've always disliked [subjectmatter] lecture classes because you can learn everything by reading a book yourself. Instead, you need to get more involved. . . . [I prefer] to be asked and be held responsible for searching [for correct forms]. First, they [correct forms] will stick in my mind. Second, I learn better. [How about your teachers' approach?] They always correct my [grammatical] errors one by one. Like I said [I do not like this approach], because you need to go and do research [on locating errors and finding correct forms]. . . . Learning will be deeper this way. [How do you react to your teachers' comprehensive WCF?] I've told my teachers several times that I like to be in charge [of correcting my errors], but nothing changes. I usually ignore their comments on some things [grammatical errors].... [Why?] Because I don't like receiving corrections without being active [in correcting my own grammatical errors]. (Nely, interview transcript, pp. 132-133)

In Excerpt 6, Nely referred to her non-English classes in justifying her positive perceptions about selective WCF. She added that selective WCF, as opposed to comprehensive WCF, would lead to longer-term learning because she would be actively involved in increasing her grammatical accuracy. However, she reported that her teachers always provided comprehensive WCF. Based on such a misalignment, her affective engagement with comprehensive WCF would probably be negative, especially if we notice that she claimed to ignore some of her teachers' comprehensive WCF due to her reported lack of active involvement in correcting her own grammar.

Overall, despite cases such as Nely (see Excerpt 6), our student participants' perceptions/preferences and their teachers' reported practices regarding the selectivity of WCF tended to be aligned, as noted in Samaneh's example, suggesting that affective learner engagement with feedback was positive in the majority of cases. Nevertheless, our findings did point to several exceptions to this general rule, where several students preferred selective WCF, as seen in the case of Nely, but received comprehensive WCF. The existing research on teachers' approaches to grammar correction (comprehensive vs. selective) as preferred by students has presented mixed findings. While a number of studies (e.g., Katayama, 2007) concluded that L2 learners welcome comprehensive WCF, other studies (e.g., Amrhein \& Nassaji, 2010) suggested that these learners tend to value selective feedback. In the Iranian EFL context, students have, in general, been noted as preferring comprehensive WCF (Rahimi, 2010) on all their grammatical errors (Jodaie \& Farrokhi, 2012). For instance, the majority of Norouzian and Farahani's (2012) student participants reported that they preferred comprehensive WCF. Our findings suggest that different 
students may hold different perceptions about comprehensive or selective WCF. Even though most of our participants preferred comprehensive correction, the exceptions, as seen in the case of Nely, point to how students' perceptions about effective learning in both English and non-English courses, among other factors, may influence their perceptions of their teachers' approaches to offering WCF. At the very least, writing teachers probably should not make overgeneralizations about their students' preferences for teachers' approaches to offering WCF in writing, a point we will discuss further.

\section{Perceptions About the Employed Methods of Providing WCF in L2 Writing}

In this section, we present the findings related to our student participants' perceptions about methods of providing WCF. Specifically, from the interview data we noticed that our participants pointed to two methods of correcting grammatical errors, and they voiced their opinions about these two methods:

- direct WCF: direct notification of grammatical errors (e.g., underlining and circling) and direct correction of errors;

- indirect WCF: direct notification of grammatical errors (e.g., underlining and circling) but indirect correction of errors (e.g., coded WCF).

Our data analysis showed that the majority of the students $(n=9)$ preferred direct $\mathrm{WCF}$, but some $(n=6)$ welcomed the indirect methods of grammar correction (perception). However, all the participants $(N=15)$ believed they primarily received direct WCF on their grammatical errors in writing (perceived practice). In Excerpt 7, Eddy, an upperintermediate student in a general-English class, pointed out that she received direct WCF and that she preferred this correction method. Eddy referred to her low grammatical competence to justify her preference.

Excerpt 7: What [WCF] is usually provided is very direct. ... They [teachers] usually use a red pen and underline or circle my errors. They also give me corrections for my errors. ... They [teachers] always underline and correct them [grammatical errors]. [Do you prefer this direct method?] Yes, because it [errors and corrections] becomes more obvious; we pay more attention to it; we learn better. . . [Do you want to receive indirect WCF?] No. This way [direct WCF] is better because I don't trust my own [grammar] knowledge. . . . If I get my writing back with lines or question marks, I don't usually know how to correct them [errors]. Of course, my teacher knows better, so I don't wanna be in charge of doing the corrections. . . . A few semesters ago, my teacher tried that [indirect WCF], but I always needed to go back to her/him for approval, because I wasn't sure whether my own corrections were accurate. (Eddy, interview transcript, p. 97)

As shown in Excerpt 7, Eddy stated that she preferred direct correction due to her low proficiency. Her responses suggest that her affective engagement with her teachers' direct WCF was mostly positive. We cannot say the same for indirect WCF, however, as we noticed that Eddy stated she had always gone back to her teachers for their "approval" when she received indirect WCF a couple of semesters ago. In fact, our analysis showed 
that the students who perceived direct feedback positively $(n=9)$ tended to rely on their teachers for accurate grammar, thus casting doubt on their own grammatical competence. By contrast, we noticed that the students who preferred indirect WCF $(n=6)$ desired to be more actively involved in increasing their grammatical accuracy by correcting some of their grammatical errors. For example, in Excerpt 8, Hoji, an advanced student in test-prep and general-English classes, touched upon the perceived advantages of indirect WCF, claiming that such feedback can lead to "deeper" and longer-term learning, compared with direct WCF. However, he added that his teachers usually used direct WCF and he pointed out that he was sometimes discouraged by direct WCF.

Excerpt 8: What they [teachers] mostly do is underline my grammar issues and write the correction above them. [Have you ever received coded feedback (e.g., SV for subject-verb agreement)?] No. The feedback is usually with the correction. I think it's because many students want to know the correct answers. Not just what errors they have. Especially, you see more of that in TOEFL classes. In those classes, students might not pay attention to things like comments that are coded. . . [What is your own preference?] I want to be more active [in increasing my grammatical accuracy in writing]. I think if they [teachers] underline something [an error] and ask me to go correct it, I can learn better. . . . To me, the learning process is more important than just the product. If you're only given the product [the correct forms], you don't learn that deeply. You may also forget it [correct forms] soon. ... [How do you feel after receiving direct WCF?] I get a little disappointed sometimes. I don't want my teacher to think that I'm stupid. [How do you react to your teachers' direct WCF?] I don't think it helps a lot with learning. I don't like just receiving corrections. I think I forget them [correct forms] soon. (Hoji, interview transcript, pp. 106-107)

Hoji's preferences for indirect WCF suggests that his affective engagement with his teachers' direct WCF might have been negative; he mentioned that direct feedback made him soon "forget about" corrections. Overall, several participants $(n=6)$ perceived direct WCF negatively, pointing out that they believed this method could only lead to short-term learning that lacked "depth." Also, as shown in Excerpt 8, direct WCF might have led to a feeling of "disappointment" in students who preferred indirect WCF. Once again, these findings underscore the importance of providing individualized WCF based on students' perceptions of what learning is about. We think that writing teachers should try to find out about how their students perceive what learning means as well as factors such as students' perceptions of their own language proficiency. For instance, learners who value indirect $\mathrm{WCF}$ and prefer to be actively engaged in the error correction process can benefit from indirect methods of error correction. This, again, means that teachers should refrain from making overgeneralizations about their students' feedback-related perceptions, especially in the Iranian EFL context.

Iranian EFL students' preferences for direct feedback have been reported in the literature. For instance, Rahimi's (2010) students overwhelmingly preferred direct grammar feedback in writing and believed that such feedback facilitated learning more effectively than indirect grammar correction. Our findings, by contrast, reveal that some Iranian EFL students might view indirect grammar correction as a means of attaining long-term learning through active learner engagement. Moreover, Hajian, Farahani, and Shirazi (2014) 
concluded that almost half of their students preferred direct WCF and that direct feedback could further motivate students to increase their grammatical accuracy in writing. While our findings show stronger positive perceptions about direct feedback, some of our participants believed that direct feedback might sometimes be discouraging. Again, we conclude that teachers should refrain from making broad generalizations about their students' preferences regarding the (in)directness of WCF.

\section{Perceptions About the Sources of WCF in L2 Writing}

Based on our data, we were able to identify several sources of WCF. These included teachers, peers, self, and outside sources (e.g., grammar books). The data analysis revealed that many of our participants $(n=12)$ preferred to receive teacher-generated WCF (perception). Similarly, most of them $(n=13)$ pointed out that their teachers were the only source of grammar feedback in their classes (perceived practice). For example, as shown in Excerpt 9, Sara, an advanced student in test-prep and general-English classes, preferred teacher-generated WCF since she tended to rely on her teachers as a source of accurate grammar. She believed that neither she nor her peers had the required grammatical competence to correct her grammatical errors in writing. Also, she referenced her psychological reactions to the possibility of her peers reading her papers, mentioning that she felt "uncomfortable" sharing her writing with her peers.

Excerpt 9: [Who provides WCF in your classes?] Just the teachers, themselves. [Why not others?] Because it [grammatical errors] is the weakness of everybody else [her peers]. Because they [peers] are not sure [about the accuracy of corrections]; I'm not either. It's better [for corrections] to be under the teacher's supervision. [How about self-correction?] No, I want my teacher to tell me [provide WCF]. . . . [Have you tried self-correction or peer-feedback in your classes?] Maybe a few times. But it's not useful for me. I don't think I have the knowledge to correct my own or my peers' errors. Even if we correct something, I won't be sure until I ask my teacher about it [corrections]. . . . Also, I don't want my peers to look at my paper. I don't feel comfortable. [How would you react if your teacher utilized peerfeedback?] Honestly, I wouldn't use those comments in my writing. I'm not sure whether they're correct. (Sara, interview transcript, p. 146)

The fact that Sara's preferences were in line with what she reported to be her teachers' practices led us to believe that Sara's affective engagement with teachergenerated WCF was probably positive. Meanwhile, her affective engagement with selfcorrection and peer-feedback would probably be negative since she mentioned that she would not feel comfortable sharing her papers with her peers and would ignore grammarcentred comments from her peers.

On the other hand, a few students $(n=3)$ thought that peer-feedback and selfcorrection could be useful in increasing their grammatical accuracy in writing. For instance, Faezeh, an intermediate student in test-prep and four-skills classes, valued peer-learning in increasing her grammatical accuracy, but limited the usefulness of peer-generated WCF to instances in which her peers' grammatical competence was higher than hers (perception). Excerpt 10 shows Faezeh's perceptions. 
Excerpt 10: It might be a good idea to correct some [grammatical] errors myself. Helps with learning. [How about peer-feedback?] It's good, too. It helps us to be less dependent on teachers. Especially if it's a proficient friend who can give you good feedback. That'd be better. Some students are too shy to correct each other's errors. I want my classmates to not be like that [shy]. If the atmosphere is like that [peers are not "shy" in providing WCF], I think peer-correction can be useful. . . . [Who actually provides WCF in your class?] It has been mostly the teachers; not a lot of my peers, not a lot of outside sources. Also, peer [feedback] is good if I feel her/his writing is better than mine. Someone who is at my level [of proficiency], I think, isn't gonna be OK. [I want] the teacher to give the final opinion. . . . [How would you react if peer-correction were used in your class?] It'd be good, but I'll ask my teacher ... I won't assume that those [peer] comments are accurate.

(Faezeh, interview transcript, pp. 101-102)

Excerpt 10 depicts a context in which Faezeh welcomed the incorporation of peerfeedback but still prioritized teacher-generated WCF. We believe peer-feedback would probably lead to her negative affective engagement with feedback because she claimed that she would not use her peers' grammar corrections without her teachers' approval. Overall, we can conclude that our students' affective engagement with teacher-generated WCF was usually positive. Although a few students $(n=3)$ viewed peer-feedback and self-correction favorably, they showed their dependence on their teachers' approval of peer-feedback and self-correction. This finding suggests that teachers might be able to use fewer teachercentred sources of grammar correction, especially for students who value student-centred correction sources. We suggest that teachers pay close attention to their students' respective preferences (e.g., superiority of teacher-generated WCF) and concerns (e.g., lack of trust in self-correction and peer-feedback) before using WCF sources that are not teachergenerated.

The high value placed on teacher feedback among students has been acknowledged in the literature on WCF in the Iranian EFL context. For instance, Jodaie, Farrokhi, and Zoghi (2011) noticed that their EFL students held teacher-generated WCF in higher regard than they did WCF from other sources (e.g., peer-feedback). A similar result was reported by Hajian, Farahani, and Shirazi (2014), who found that $90 \%$ of their students preferred to receive teacher-generated WCF. Aiming to explain the popularity of teacher-generated WCF, Kaivanpanah, Alavi, and Sepehrinia (2015) pointed out that students' feedbackrelated perceptions "are certainly affected by the contextual factors and socio-cultural issues concerning the role and power of teachers in particular contexts" (p. 89). In a similar vein, Zohrabi, Torabi, and Baybourdiani (2012) stressed the teacher-dominated nature of L2 teaching in Iran and claimed "the traditional teacher-led or administer-centred learning are used more frequently than student-led learning. A student is viewed as learner, who passively receives information and teacher's role is information provider or evaluator to monitor learners to get the right answer" (p. 20). A few of our participants also brought up the importance of the psychological factors in justifying their preferences for teachergenerated WCF (see Excerpt 9). Ghahari and Sedaghat (2018) touched upon the role of psychological factors (e.g., feelings of embarrassment) as potential hindrances in using peer-feedback in the Iranian EFL context. Overall, our findings add further evidence for the popularity of teacher-generated grammar-centred WCF in the Iranian EFL context. 


\section{General Discussion and Conclusion}

In this study, we aimed to explore 15 Iranian EFL students' WCF-related perceptions and their teachers' reported practices. We also set out to identify any discrepancies in these perceptions and practices to explain the students' affective engagement with the following aspects of WCF:

- relative importance of WCF compared with feedback on content and/or organization,

- selective and comprehensive WCF,

- (in)directness of WCF, and

- $\quad$ sources of WCF (e.g., teachers and peers).

Drawing upon a few existing studies (e.g., Ellis, 2010; Han \& Hyland, 2015), we assumed that any perception-practice discrepancies might lead to our students' negative affective engagement with feedback. Our data analysis helped identify several cases of positive (i.e., aligned student perceptions and teacher practices) and negative (i.e., misaligned student perceptions and teacher practices) affective engagement with feedback. As Rummel and Bitchener (2015) concluded, learning is more likely to occur if students receive the type of feedback they view as useful, important, and/or effective. Therefore, we conclude that our participants' negative engagement with feedback could lead to unsatisfactory gains in their grammatical accuracy. Here, we revisit our initial research questions and explain the important findings of the study.

First, the data analysis revealed that our students reported that they generally prioritized feedback on content development and organization over WCF, but they reported that their teachers, contrary to what these students preferred, primarily stressed grammatical accuracy in writing. This discrepancy suggests that the students might have received excessive grammar-centred feedback, while they chiefly sought feedback on content and organization. Overall, this finding suggests that

- teachers might have provided one type of feedback to all of their students,

- the students held distinctive perceptions about feedback on various areas of L2 writing, and

- discrepant teacher practices and student perceptions could potentially lead to the students' negative affective engagement with feedback.

In fact, several students reported that they would ignore their teachers' overcorrection of grammatical errors. As brought up by a few students, such overcorrection might also be disappointing to learners.

Our findings also suggest that student preferences and teacher practices regarding various aspects of WCF tended to be aligned. Specifically, the students mostly preferred to receive grammar-centred WCF that was (a) comprehensive, (b) direct, and (c) teachergenerated. Although we reported a number of discrepant student perceptions and teacher practices, the students' responses suggest that their affective engagement with various aspects of the WCF they received may have been positive. These findings underscore the importance of familiarity with learners' feedback-related perceptions and the value of 
individualized feedback in L2 writing. Han (2017) also concluded that teachers should consider learners' feedback-related perceptions when providing WCF. Our findings suggest that overgeneralized assumptions about learners' preferences might lead to unsatisfactory gains in grammatical accuracy as a result of learners' negative affective engagement with feedback. For instance, some of our participants reported that indirect methods of WCF and student-centred sources of WCF (e.g., peer-feedback) helped them attain longer-term and deeper learning (i.e., increases in grammatical accuracy). Han (2017) similarly stated that "the attentional resources allocated to an error with WCF were influenced by students' beliefs about the type of WCF" (p. 140). Han's finding is especially relevant to our study because some of our participants reportedly received the feedback that they perceived unfavourably. This leads us to believe that negative perceptions might elicit insufficient attention to the provided WCF (e.g., Excerpts 1, 6, 7, and 8), which in turn affects students' accuracy gains.

Our findings also suggest that the students' feedback-related perceptions might be contradictory. For example, even though many of the participants claimed that they valued feedback on content and organization more highly than they did grammar-centred WCF, their preferences for comprehensive, direct, and teacher-generated WCF indicate that the majority of them might have sought grammatical accuracy in writing. As Ferris (2014) noted, practices such as peer-feedback, selective correction, and indirect feedback are beneficial to learners' autonomy and longer-term gains in their grammatical accuracy. However, our findings suggest that Iranian EFL participants might hold WCF-related preferences that are highly teacher-centred. Overall, we can conclude that our student participants might have placed excessive emphasis (either consciously or subconsciously) on grammatical accuracy in writing, despite what they may have said about preferring to receive feedback on content and organization, sometimes over-relying on their teachers.

Our findings point to a number of pedagogical implications for teachers, especially those in the Iranian EFL context. First, writing teachers should familiarize their students with more learner-centred approaches to grammar correction. Our participant students seemed doubtful about the effectiveness of student-centred WCF approaches, such as peerfeedback, sometimes for psychological reasons. Teachers should create a learner-centred and learner-friendly climate in class where students are not afraid of, for instance, providing and receiving peer-feedback or engaging in self-correction. This can in turn help teachers to hold their students accountable in the process of increasing their grammatical accuracy. Han (2017) reported that students' beliefs and perceptions about feedback can be changed over time. Thus, upon building effective rapport with their students, teachers can change student perceptions that do not conform to what is recommended by the available literature (e.g., overuse of teacher-generated WCF). Ghahari and Sedaghat (2018) also concluded that raising students' awareness about the benefits of peer-feedback through teacher intervention can change negative perceptions about this source of error correction in the Iranian EFL context. Teachers should be aware of these latest student-centred approaches to WCF because teachers, at least as seen through their students' reports, tend to provide the kinds of feedback that are considered old-fashioned in the literature (see Ferris, 2014, for a list of recommended feedback practices).

Our findings lead us to believe that our student participants can be divided into two groups. Although both groups preferred to increase their grammatical accuracy in writing, they reported different preferences for WCF approaches. The first group sought teachercentred grammar correction through, for instance, direct WCF. However, the available 
literature (see Ferris, 2014) does not support the excessive incorporation of teachergenerated, direct, comprehensive WCF. Based on our findings, this group's affective engagement with WCF seems positive because these learners' teachers reportedly provided WCF that was well-aligned with the identified learner perceptions. The second group of students also preferred WCF, but through more learner-centred approaches (e.g., selective WCF and self-correction). As our analysis showed, the second group did not seemingly receive their preferred WCF, so their affective engagement with the received WCF is likely negative, thereby possibly affecting their accuracy gains. In fact, these students stated that they might even ignore excessively teacher-centred WCF.

Again, the above findings draw our attention to the importance of effective communication between teachers and students, especially in the Iranian EFL context. For instance, through needs analyses teachers can explore the areas in which their students' preferences and their own practices might diverge. This can enable teachers to provide individualized WCF to students with various perceptions and preferences. Such effective teacher-student rapport can promote the efficacy of WCF and increase learners' accuracy gains. For example, if learners prefer to receive student-centred WCF, teachers might choose to employ such WCF approaches as peer-feedback, selective WCF, and indirect WCF, which can help keep students accountable. We should again emphasize that, according to our findings, L2 learners hold different WCF-related perceptions, so teachers should refrain from making overgeneralizations about their students' perceptions/preferences.

The present study was the first known qualitative attempt at exploring Iranian EFL students' WCF-related perceptions, their teachers' practices as reported by these students, and their affective engagement with WCF. We hope to expand on the current study by analyzing samples of student writing with feedback on it to delve more deeply into the patterns of learner engagement with feedback. In particular, as Ellis (2010) and Han and Hyland (2015) proposed, students' affective engagement with feedback is generally their first reaction to feedback and is particularly important because students' negative affective engagement might not lead to positive behavioural and cognitive engagement, resulting in unsatisfactory attainment of learning outcomes. In future projects we aim to investigate students' cognitive and behavioural engagement with feedback to see how their affective engagement with feedback might influence their ultimate gains in grammatical accuracy. Nonetheless, we think our findings on learners' affective engagement provide novel insights into the patterns of student engagement with different aspects of WCF.

Correspondence should be addressed to Hooman Saeli.

Email: hsaeli@utk.edu

\section{References}

Amrhein, H. R., \& Nassaji, H. (2010). Written corrective feedback: What do students and teachers think is right and why? Canadian Journal of Applied Linguistics, 13(2), 95-127.

Bitchener, J., Young, S., \& Cameron, D. (2005). The effect of different types of corrective feedback on ESL student writing. Journal of Second Language Writing, 14(3), 191 205. 
Chandler, J. (2003). The efficacy of various kinds of error feedback for improvement in the accuracy and fluency of L2 student writing. Journal of Second Language Writing, 12(3), 267-296.

Corbin, J., \& Strauss, A. (2014). Basics of qualitative research: Techniques and procedures for developing grounded theory. New York, NY: Sage Publications.

Ellis, R. (2010). A framework for investigating oral and written corrective feedback. Studies in Second Language Acquisition, 32(2), 335-349.

Elwood, J. A., \& Bode, J. (2014). Student preferences vis-à-vis teacher feedback in university EFL writing classes in Japan. System, 42(1), 333-343.

Farhady, H., Hezaveh, F. S., \& Hedayati, H. (2010). Reflections on foreign language education in Iran. TESL-EJ, 13(4), 1-18.

Fazio, L. L. (2001). The effect of corrections and commentaries on the journal writing accuracy of minority- and majority-language students. Journal of Second Language Writing, 10(4), 235-249.

Ferris, D. R. (1995). Student reactions to teacher response in multiple-draft composition classrooms. TESOL Quarterly, 29(1), 33-53.

Ferris, D. R. (1999). The case for grammar correction in L2 writing classes: A response to Truscott (1996). Journal of Second Language Writing, 8(1), 1-11.

Ferris, D. R. (2014). Responding to student writing: Teachers' philosophies and practices. Assessing Writing, 19, 6-23.

Ghahari, S., \& Sedaghat, M. (2018). Optimal feedback structure and interactional pattern in formative peer practices: Students' beliefs. System, 74, 9-20.

Hajian, L., Farahani, A. A. K., \& Shirazi, M. A. (2014). A study of students' and teachers' preferences and attitudes towards correction of classroom written errors in Iranian EFL context. International Journal of Applied Linguistics and English Literature, 3(5), 287-297.

Han, Y. (2017). Mediating and being mediated: Learner beliefs and learner engagement with written corrective feedback. System, 69, 133-142.

Han, Y., \& Hyland, F. (2015). Exploring learner engagement with written corrective feedback in a Chinese tertiary EFL classroom. Journal of Second Language Writing, 30, 31-44.

Haseli Songhori, M. (2012). Exploring the congruence between teachers' and students' preferences for form-focused instruction: Isolated or integrated. The Asian EFL Journal, 61, 4-23.

Hedgcock, J., \& Lefkowitz, N. (1994). Feedback on feedback: Assessing learner receptivity to teacher response in L2 composing. Journal of Second Language Writing, 3(2), 141-163.

Horwitz, E. K. (1999). Cultural and situational influences on foreign language learners' beliefs about language learning: A review of BALLI studies. System, 27(4), 557576.

Jodaie, M., \& Farrokhi, F. (2012). An exploration of private language institute teachers' perceptions of written grammar feedback in EFL classes. English Language Teaching, 5(2), 58-67.

Jodaie, M., Farrokhi, F., \& Zoghi, M. (2011). A comparative study of EFL teachers' and intermediate high school students' perceptions of written corrective feedback on grammatical errors. English Language Teaching, 4(4), 36-48. 
Kaivanpanah, S., Alavi, S. M., \& Sepehrinia, S. (2015). Preferences for interactional feedback: Differences between learners and teachers. The Language Learning Journal, 43(1), 74-93.

Katayama, A. (2007). Students' perceptions of corrective feedback to oral errors. Asian EFL Journal, 9(4), 289-305.

Kern, R. G. (1995). Students' and teachers' beliefs about language learning. Foreign Language Annals, 28(1), 71-92.

Lee, I. (2005). Error correction in the L2 writing classroom: What do students think? TESL Canada Journal, 22(2), 1-16.

Lee, I. (2008). Student reactions to teacher feedback in two Hong Kong secondary classrooms. Journal of Second Language Writing, 17(3), 144-164.

Leki, I. (1991). The preferences of ESL students for error correction in college-level writing classes. Foreign Language Annals, 24(3), 203-218.

Leki, I. (2001). Hearing voices: L2 students' experiences in L2 writing courses. In P. K. Matsuda \& T. Silva (Eds.), On second language writing (pp. 17-28). Mahwah, NJ: Lawrence Erlbaum.

Montgomery, J. L., \& Baker, W. (2007). Teacher-written feedback: Student perceptions, teacher self-assessment, and actual teacher performance. Journal of Second Language Writing, 16(2), 82-99.

Norouzian, R., \& Farahani, A. A. K. (2012). Written error feedback from perception to practice: A feedback on feedback. Journal of Language Teaching and Research, 3(1), 11-22.

Radecki, P., \& Swales, J. (1988). ESL student reaction to written comments on their written work. System, 16(3), 355-365.

Rahimi, M. (2010). Iranian EFL students' perceptions and preferences for teachers' written feedback: Do students' ideas reflect teachers' practice? The Journal of Teaching Language Skills, 2(2), 75-98.

Rummel, S., \& Bitchener, J. (2015). The effectiveness of written corrective feedback and the impact Lao learners' beliefs have on uptake. Australian Review of Applied Linguistics, 38(1), 66-84.

Saeli, H., \& Cheng, A. (2019). Effects of L1 writing experiences on L2 writing perceptions: Evidence from an EFL context. Reading \& Writing Quarterly. doi.org/10.1080/10573569.2019.1579129

Schulz, R. A. (2001). Cultural differences in student and teacher perceptions concerning the role of grammar instruction and corrective feedback: USA-Colombia. The Modern Language Journal, 85(2), 244-258.

Sheen, Y. (2007). The effect of focused written corrective feedback and language aptitude on ESL learners' acquisition of articles. TESOL Quarterly, 41(2), 255-283.

Sheen, Y., Wright, D., \& Moldawa, A. (2009). Differential effects of focused and unfocused written correction on the accurate use of grammatical forms by adult ESL learners. System, 37(4), 556-569.

Shishavan, H. B. (2010). The relationship between Iranian English language teachers' and learners' gender and their perceptions of an effective English language teacher. English Language Teaching, 3(3), 3-10.

Shishavan, H. B., \& Sadeghi, K. (2009). Characteristics of an effective English language teacher as perceived by Iranian teachers and learners of English. English Language Teaching, 2(4), 130-143. 
Truscott, J. (1996). The case against grammar correction in L2 writing classes. Language Learning, 46(2), 327-369.

Yang, M., Badger, R., \& Yu, Z. (2006). A comparative study of peer and teacher feedback in a Chinese EFL writing class. Journal of Second Language Writing, 15(3), 179200.

Zheng, Y., \& Yu, S. (2018). Student engagement with teacher written corrective feedback in EFL writing: A case study of Chinese lower-proficiency students. Assessing Writing, 37, 13-24.

Zohrabi, M., Torabi, M. A., \& Baybourdiani, P. (2012). Teacher-centered and/or studentcentered learning: English language in Iran. English Language and Literature Studies, 2(3), 18-30. 


\section{Appendix}

\section{The Interview Protocol}

\section{Students' Personal Information:}

Age; educational background; academic degree; English courses taken; English learning experience in English institutes; classes taken; four-skills? TOEFL iBT? IELTS?

\section{Students' Perceptions about Various Aspects of Grammar-centred WCF:}

1. Do your English classes involve writing? If so, how much? In writing, how do rankorder the importance of grammar, content, organization, and any other important factors you might have in mind? How about feedback on these areas? How about you teachers' practices? Explain, please.

2. Do your teachers correct your grammatical errors in writing? If so, what forms of error correction do you usually receive? Which methods? Direct? Indirect? One-on-one conferences with teachers? Which ones do you prefer? Discuss, please.

3. How much grammar correction do you receive? On every error? Selective correction? Which one do you prefer? Discuss, please.

4. Who gives you corrections on your grammatical errors in writing? Teachers? Peers? Yourself? Outside sources? Which ones do you prefer? Discuss, please.

5. Do you have any final comments on the methods of error correction which are used in your classes? Discuss, please. 